\title{
Open Heart Surgery at Patient's Own Temperature Without Active Cooling
}

\author{
Mehmet Kaplan, MD, ${ }^{1}$ Anil Karaagac, MD,${ }^{1}$ Tolga Can, MD,${ }^{1}$ Sahin Yilmaz, MD,${ }^{2}$ \\ M. Inanc Yesilkaya, MD, ${ }^{1}$ Adlan Olsun, $M D,{ }^{1}$ Hakki Aydogan, $\mathrm{MD}^{1}$ \\ ${ }^{1}$ Department of Cardiovascular Surgery and ${ }^{2}$ Department of Anesthesiology, Dr. Siyami Ersek Thoracic and Cardiovascular \\ Surgery Training and Research Hospital, Istanbul, Turkey
}

\section{ABSTRACT}

Background: Hypothermia is a method of myocardial protection in cardiac surgery. This protection occurs by decreasing the metabolic demands, however, it creates susceptibility to various problems. In this study, we investigated patients operated on under normothermia (at the patient's own temperature) and hypothermia for postoperative differences.

Methods: The study was conducted between June 2015 and September 2016 with 167 patients. The patients were divided into two groups in accordance with our routine clinical practice: the normothermic group (native temperature goup; intraoperative body temperature $\geq 34^{\circ} \mathrm{C}$ ), and the hypothermic group intraoperative body temperature $<34^{\circ} \mathrm{C}$ $-\geq 28^{\circ} \mathrm{C}$ ). Preoperative and postoperative data of patients were recorded and the two groups were compared.

Results: There was no significant difference between the two groups in terms of cross clamp time, cardiopulmonary bypass time, awakening and extubation times, intensive care unit and hospital stay, drainage, mean serum lactate levels, arrhytmia, all causes infection, renal insufficiency, neurologic complications, myocardial infarction, or mortality $(P>.05)$. Inotrope and transfusion requirements were found to be statistically significantly lower in the normothermic group than the hypothermic group $(P<.05)$.

Conclusion: Although hypothermia is commonly used in cardiac surgery, it has harmful effects. We believe that cardiac surgery can safely be performed at a patient's own temperature without active cooling to avoid these dangers.

\section{INTRODUCTION}

The use of systemic cooling and the level of cooling used in cardiac surgery have been continuously discussed. However, there is no consensus among cardiac surgeons on a definition or classification of hypothermia. There have been many studies in literature discussing the positive and negative aspects of active cooling [Greason 2014; Ho 2011; Warm Heart Investigators 1994].

Received February 9, 2018; received in revised form March 7, 2018; accepted March 9, 2018.

Correspondence: Mehmet Kaplan, MD, Dr. Siyami Ersek Thoracic and Cardiovascular Surgery Training and Research Hospital, Tibbiye Street, No: 13, Haydarpasa, 34668, Uskudar, Istanbul, Turkey; +90-216-542-44-64, +90-532-270-36-33 (e-mail: drmebmetkaplan@gmail.com).
Normothermia, mild, and moderate hypothermia definitions are mostly based on individual clinics' routine practices, and are often different temperature values. The habit of using hypothermia in cardiac surgery has been reduced over the years, and there is a shift towards the direction of mild hypothermia $\left(32-34^{\circ} \mathrm{C}\right)$ and normothermia $\left(34-37^{\circ} \mathrm{C}\right)$. In some studies, systemic hypothermia is associated with negative effects on cardiac, renal, and endocrine functions, as well as wound healing and the coagulation system [Greason 2014; Ho 2011]. The same studies concluded that cardiac surgery can be safely performed with normothermia and mild hypothermia without active cooling.

In this study, we analyzed the patients that were operated on at their own temperature without active cooling.

Table 1. Preoperative Demographic Data of Patients

\begin{tabular}{|c|c|c|}
\hline \multirow[t]{2}{*}{ Age (years) } & Min-Max (Median) & $25-83(61)$ \\
\hline & Mean \pm Sd & $60.4 \pm 9.9$ \\
\hline \multirow[t]{2}{*}{ Gender; n (\%) } & Female & $37(22.2)$ \\
\hline & Male & $130(77.8)$ \\
\hline \multirow[t]{2}{*}{ Weight (kg) } & Min-Max (Median) & $40-120(78)$ \\
\hline & Mean $\pm S d$ & $79.4 \pm 12.6$ \\
\hline \multirow[t]{2}{*}{ Height (m) } & Min-Max (Median) & $1.4-1.9(1.70)$ \\
\hline & Mean $\pm S d$ & $1.7 \pm 0.1$ \\
\hline \multirow[t]{2}{*}{ BMI $\left(\mathrm{kg} / \mathrm{m}^{2}\right)$} & Min-Max (Median) & $17.8-40(27.5)$ \\
\hline & Mean $\pm S d$ & $27.9 \pm 4.0$ \\
\hline \multirow[t]{2}{*}{ DM; n (\%) } & No & $86(51.5)$ \\
\hline & Yes & $81(48.5)$ \\
\hline \multirow[t]{2}{*}{ HT; n (\%) } & No & $80(47.9)$ \\
\hline & Yes & $87(52.1)$ \\
\hline \multirow[t]{2}{*}{ EF } & Min-Max (Median) & $25-65(55)$ \\
\hline & Mean $\pm S d$ & $51.5 \pm 10.4$ \\
\hline \multirow[t]{2}{*}{ EUROSCORE II } & Min-Max (Median) & $0.9-15.3(1.5)$ \\
\hline & Mean \pm Sd & $2.2 \pm 1.9$ \\
\hline
\end{tabular}

BMI indicates body mass index; DM, diabetes mellitus; $\mathrm{HT}$, hypertension; $\mathrm{EF}$, ejection fraction; $\mathrm{Sd}$, standard deviation. 
Table 2. Comparison of the Demographical Data Between Groups

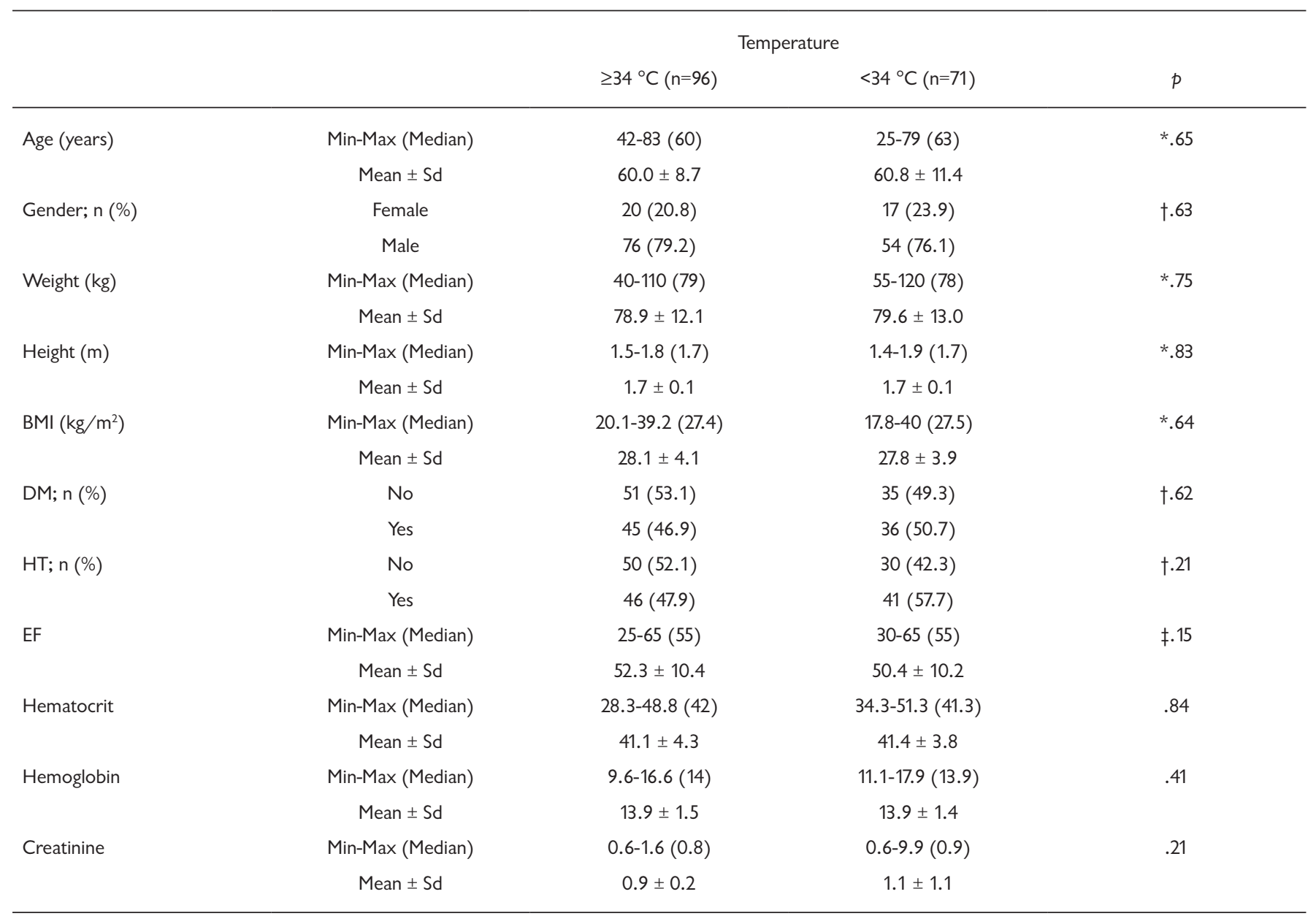

BMI indicates body mass index; DM, diabetes mellitus; $\mathrm{HT}$, hypertension; $\mathrm{EF}$, ejection fraction; Sd, standard deviation.

*Student $\mathrm{t}$ Test; $\nmid$ Pearson Chi-Square Test; $\ddagger$ Mann Whitney $U$ Test

\section{METHODS}

\section{Patient Data}

The study was conducted between June 2015 and September 2016 in the Siyami Ersek Thoracic and Cardiovascular Surgery Training and Research Hospital at the Department of Cardiovascular Surgery, Istanbul, Turkey. Of the 167 patients included, $22.2 \%(\mathrm{n}=37)$ were female and $77.8 \%(\mathrm{n}=130)$ were male. The ages of the patients ranged from 25 to 83 , with a mean of $60.4 \pm 9.9$ years (Table 1). The study protocol was approved by the Siyami Ersek Thoracic and Cardiovascular Surgery Training and Research Hospital Ethics Committee. Informed consent was obtained from all of the patients.

\section{Study Groups}

The patients were divided into two groups in accordance with our routine clinical practice: the normothermic group (the native temperature group; intraoperative body temperature $\geq 34^{\circ} \mathrm{C}$ ) and the hypothermic group (intraoperative body temperature $<34^{\circ} \mathrm{C}-\geq 28^{\circ} \mathrm{C}$ ). Of all the patients, $42.5 \%(\mathrm{n}=71)$ were operated on under $34^{\circ} \mathrm{C}$ (mean temperature $\left.30.6 \pm 1.95^{\circ} \mathrm{C}\right)$, and $57.5 \%(\mathrm{n}=$ 96) were operated on above $34^{\circ} \mathrm{C}$ (mean temperature 34.7 $\left.\pm 0.47^{\circ} \mathrm{C}\right)$.

\section{Operative Technique and Systemic Temperature Management}

Operations were performed under cardiopulmonary bypass $(\mathrm{CPB})$ following routine sternotomy and ascending aortic arterial and right atrial venous cannulation. The patients in the normothermic group were operated at the patient's own temperature if the temperature was above $34^{\circ} \mathrm{C}$ (while preventing further drops in temperature with active warming), and at $34^{\circ} \mathrm{C}$ if the patient's temperature was lower than $34^{\circ} \mathrm{C}$ (also achieved with active warming). The mean temperature of the hypothermic group was $30.6^{\circ} \mathrm{C}\left(1\right.$ patient at $33.5^{\circ} \mathrm{C}, 3$ patients at $33^{\circ} \mathrm{C}, 38$ patients at $32^{\circ} \mathrm{C}, 4$ patients at $30^{\circ} \mathrm{C}$ and 25 patients at $\left.28^{\circ} \mathrm{C}\right)$. 
Table 3. Types of Operations

\begin{tabular}{lccc}
\hline & \multicolumn{3}{c}{ Temperature } \\
Type of Operation & $\begin{array}{c}\text { Group } 1 \\
\left(\geq 34^{\circ} \mathrm{C}\right)\end{array}$ & $\begin{array}{c}\text { Group } 2 \\
\left(<34^{\circ} \mathrm{C}\right)\end{array}$ & Total $(\%)$ \\
\hline CABG & 89 & 53 & $142(85)$ \\
AVR & 2 & 4 & $6(3.6)$ \\
AVR+MVR & 1 & 3 & $4(2.4)$ \\
CABG+Pseudoanurysm Repair & 1 & 2 & $3(1.8)$ \\
AVR+MVR+TDV & 1 & 1 & $2(1.2)$ \\
AVR+CABG & 0 & 2 & $2(1.2)$ \\
AVR+ARE+TDV & 0 & 1 & $1(0.6)$ \\
AVR+MVR+CABG & 0 & 1 & $1(0.6)$ \\
AVR+ARE+MVR & 0 & 1 & $1(0.6)$ \\
AVR+ARE+MVR+TDV & 1 & 0 & $1(0.6)$ \\
MVR+CABG & 1 & 0 & $1(0.6)$ \\
MVR+TDV & 0 & 1 & $1(0.6)$ \\
MVR+TDV+CABG & 0 & 1 & $1(0.6)$ \\
Redo CABG & 0 & 1 & $1(0.6)$ \\
Total & 96 & 71 & 167 \\
\hline
\end{tabular}

AVR indicates aortic valve replacement; ARE, aortic root enlargement; CABG, coronary artery bypass grafting; MVR, mitral valve replacement; TDV, tricuspid valve de Vega annuloplasty.

Operations were performed by a single surgical team. Antegrade warm blood cardioplegia was perfused intermittantly (every 20 minutes) in all cases. We did not use topical myocardial cooling in any of the patients.

\section{Distribution of Cases}

When analysing the types of operations of the patients in our study, the majority had isolated coronary artery bypass grafting (CABG) $(\mathrm{n}=142,85 \%)$. Valvular operations were performed on $16(9.6 \%)$ patients, as $5(3 \%)$ patients underwent combined valve + bypass graft operations. Three $(1.8 \%)$ patients underwent femoral pseudoaneurysm repair with CABG, and in $1(0.6 \%)$ patient, a re-do CABG was performed. The majority of cases in both groups had CABG (Table 3).

In June 2015, we decided to operate on our patients at their own temperature in normothermic conditions to avoid the harmful effects of hypothermia. However, the decision of whether to use hypothermia was made by the performing surgeron during the period of transition. We have compared the results of this period of transition from hypothermia to normothermia. This is the reason for the difference in the distribution of the cases among the groups.

\section{Anesthetic Management}

All patients received $5 \mathrm{mg}$ of diazepam orally the night before, and $4 \mathrm{mg}$ of midazolam intramuscularly one hour before surgery as premedication. Electrocardiogram, pulse oximetry, direct blood pressure monitoring via radial arterial catheterisation, and cerebral blood flow with NIRS (near infrared spectroscopy, INVOS 3100 Somanetics Corporation, Troy, MI, USA) were recorded. The temperature measurements were taken with esophageal probes.

The same anesthetic protocol for cardiac surgery and thoracic aortic surgery was applied in all cases. Anesthesia was induced with fentanyl citrate $(20 \mathrm{mcg} / \mathrm{kg})$, rocuronium bromide $(0.5 \mathrm{mg} / \mathrm{kg})$, and propofol $(1 \mathrm{mg} / \mathrm{kg})$. Anesthesia was maintained with fentanyl citrate $(10 \mathrm{mcg} / \mathrm{kg})$, propofol $(1 \mathrm{mg} / \mathrm{kg})$, and rocuronium bromide $(0.15 \mathrm{mg} / \mathrm{kg})$ throughout the operation.

\section{Statistical Analysis}

The NCSS 2007 (Number Cruncher Statistical System; Kaysville, Utah, USA) program was used for statistical analyses. Data were analyzed using descriptive statistical methods (mean, standard deviation, median, frequency, rate, minimum, maximum), the Student's t-test in the two-group comparisons of the normal distribution of quantitative data, and the Mann-Whitney $\mathrm{U}$ in the two-group comparisons in abnormal distribution. The Wilcoxon Signed Ranks test was used in the comparison with normal distribution within each group, and the Pearson chi-square test and Fisher's exact test were used for the comparison of qualitative data. $P$ values of $P$ $<.01$ and $P<.05$ values were considered significant.

\section{RESULTS}

\section{Demographic Data of the Patients}

There was no significant difference between the two groups in terms of age, gender, height, weight, body mass index (BMI), diabetes mellitus (DM), hypertension (HT), ejection fraction (EF), preoperative hemoglobin, hematocit, or serum creatinine values $(P>.05)$. There was also no significant difference in EUROSCORE II scores among groups, which is routinely used for preoperative risk calculation $(P>.05)$ (Table 2).

\section{Cross Clamp Time, Cardiopulmonary Bypass Time, Awak- ening Time, Extubation Time, Intensive Care Unit Stay, Hospital Stay}

Cross clamp (CC) time, CPB time, awakening time, extubation time, and intensive care unit (ICU) stay and hospital stay times were shorter in the normothermic group, but the difference was not statistically significant $(P>.05)$ (Table 4).

\section{Postoperative Consciousness}

We observed that postoperative wakefulness, orientation, and cooperation of the patients in the normothermic group were not clinically compromised, and they could be safely mobilized at early periods.

\section{Postoperative Data}

There was no statistically significant difference in drainage, urine output, serum lactate levels, arrhythmia, all causes of infection, renal insufficiency, neurological complications 
Table 4. Comparison of Ventilation, Cross Clamp, Cardiopulmonary Bypass Times, and Durations of Intensive Care Unit and Hospital Stay Between Groups

\begin{tabular}{|c|c|c|c|c|}
\hline Awakening time (hours) & Mean \pm Sd & $6.5 \pm 2.3$ & $7.8 \pm 5.4$ & \\
\hline Extubation time (hours) & Min-Max (Median) & 5-19(9) & $4-44(10)$ & .38 \\
\hline \multirow[t]{2}{*}{ CPB time (min) } & Min-Max (Median) & $46-225(46)$ & $40-371(40)$ & .26 \\
\hline & Mean \pm Sd & $127.8 \pm 36$ & $137 \pm 50.2$ & \\
\hline \multirow[t]{2}{*}{ CC time (min) } & Min-Max (Median) & 23-191 (90) & $23-306(97)$ & .30 \\
\hline & Mean \pm Sd & $92.9 \pm 31$ & $101.7 \pm 45.7$ & \\
\hline ICU stay (days) & Min-Max (Median) & $1-4(1)$ & $1-12(1)$ & .47 \\
\hline
\end{tabular}

CPB indicates cardiopulmonary bypass; CC, cross clamp; ICU, intensive care unit; Sd, standard deviation.

*Mann Whitney U Test

(stroke, transient ischemic attack [TIA], confusion), myocardial infarction $(\mathrm{MI})$, or mortality between groups $(P>.05)$.

\section{Inotrope Need}

The inotropic requirement of the patients operated on under $34^{\circ} \mathrm{C}(\mathrm{n}=33,46.5 \%)$ was significantly higher than the patients operated on over and at $34^{\circ} \mathrm{C}(\mathrm{n}=26,27.1 \%)$ $(P=.01 ; P<.05)$. We could not explain the greater inotropic need in the hypothermic group with only the patient's intraoperative temperature.

\section{Reoperation Rate}

There was also a statistically significant difference in the means of reoperation rate between the two groups; reoperation rate in the normothermic group $(9.4 \%, \mathrm{n}=9$ ) was significantly lower than in the hypothermic group $(22.5 \%$, $\mathrm{n}=16)(P=.02 ; P<.05)$. However, we could not conclude that the only cause of the higher reoperation rate in the hypothermic group was the intraoperative temperature of the patient. When we looked at the causes of reoperations, the rates of reoperations performed for bleeding or tamponade were lower in the normothermic group $(n=5,5.2 \%)$ than in the hypothermic group $(\mathrm{n}=9,12.6 \%)$, but the difference was not statistically significant $(P=.08 ; P>.05)$.

\section{Transfusion Rate}

We aimed for all patients to undergo open heart surgery without using blood or blood products. The transfusions were analyzed and compared between two groups. In the hypothermic group, 34 patients (47.9\%) needed blood transfusions, and 4 were preoperatively anemic. In the normothermic group, 31 patients $(32.3 \%)$ needed transfusions, and 10 were anemic preoperatively.

When the patients who were preoperatively anemic were excluded, the rate of transfusion significantly decreased in the normothermic group $(24.4 \%$ in the normothermic group compared to $44.7 \%$ in the hypothermic group). The need for transfusion in the hypothermic group was statistically significantly higher than that of the normothermic group $(P=.04$; $P<.05)$ (Table 5).

\section{DIscussioN}

Hypothermia has been recognized and long been used as a method for myocardial protection in cardiac surgery. However, there are ongoing debates about the benefits and risks of hypothermia achieved by active cooling. There is no consensus about the definition and classification of hypothermia among surgeons in literature. Physicians propose different classifications and definitions for hypothermia for normothermia according to their own routine practices [Ho 2011; Mackowiak 1992].

In a study by Mackowiak et al, mean temperature of the healthy population was found to be $36.8 \pm 0.4^{\circ} \mathrm{C}$, and temperatures above $36.0^{\circ} \mathrm{C}$ were suggested to be proper to define normothermia [Mackowiak 1992]. In a meta-analysis by Ho et al, temperatures above $34^{\circ} \mathrm{C}$ were considered as normothermia, and temperatures below $34^{\circ} \mathrm{C}$ as hypothermia for patients underwent surgery with CPB [Ho 2011]. Based on this meta-analysis and our routine clinical practice, we have also defined normohermia as temperatures above $34^{\circ} \mathrm{C}$ (patient's own temperature) and hypothermia as temperatures below $34^{\circ} \mathrm{C}$. 
Table 5. Comparison of the Postoperative Data Between Groups

\begin{tabular}{|c|c|c|c|c|}
\hline Drainage, $\mathrm{ml}$ & Mean \pm Sd & $590.1 \pm 315.1$ & $586.62 \pm 267.8$ & \\
\hline Urine output, $\mathrm{ml}$ & Min-Max (Median) & $2050-7050(4000)$ & $850-7300(3750)$ & .48 \\
\hline \multirow[t]{2}{*}{ Lactate levels, $\mathrm{mmol} / \mathrm{L}$} & Min-Max (Median) & $0.7-9(1.8)$ & $0.8-15(2)$ & .10 \\
\hline & Mean \pm Sd & $2 \pm 1.1$ & $2.5 \pm 2$ & \\
\hline \multirow[t]{2}{*}{ Arrhytmia; n (\%) } & No & $66(68.8)$ & $51(71.8)$ & $* .67$ \\
\hline & Yes & $30(31.3)$ & $20(28.2)$ & \\
\hline Need for inotrope; n (\%) & No & $70(72.9)$ & $38(53.5)$ & $* \neq .01$ \\
\hline \multirow[t]{2}{*}{ Renal insufficiency; n (\%) } & No & $94(97.9)$ & $68(95.8)$ & $\dagger .65$ \\
\hline & Yes & $2(2.1)$ & $3(4.2)$ & \\
\hline \multirow[t]{2}{*}{ Reoperation (all causes); n (\%) } & No & $87(90.6)$ & $55(77.5)$ & $* \neq .02$ \\
\hline & Yes & $9(9.4)$ & $16(22.5)$ & \\
\hline \multirow[t]{2}{*}{ Neurologic complications; n (\%) } & No & $93(96.9)$ & $67(94.4)$ & $\dagger .46$ \\
\hline & Yes & $3(3.1)$ & $4(5.6)$ & \\
\hline \multirow[t]{2}{*}{ Ml; n (\%) } & No & $94(97.9)$ & $70(98.6)$ & $\dagger 1.00$ \\
\hline & Yes & $2(2.1)$ & $1(1.4)$ & \\
\hline
\end{tabular}

Sd indicates standard deviation; MI, myocardial infarction

*Pearson Chi-Square Test; $†$ Fisher’s Exact Test; $\ddagger P<.05$

Systemic hypothermia reduces the oxygen comsumption of tissues and thereby increases tolerance for ischemia [Warm Heart Investigators 1994]. For this reason, hypothermia is used widely to prevent end-organ damage in cardiac surgery. However, systemic hypothermia is associated with impaired cardiac and renal functions, increased risk for coagulopathies, increased transfusion requirements, and disturbances in wound healing [Ho 2011].

Despite tissue protection benefits, it is difficult to determine the effect of hypothermia on mortality and morbidity due to other metabolic problems that occur. Recent studies have reported that hypothermia achieved by active cooling in cardiac surgery is not superior to mild hypothermia or normothermia in terms of complication rates [Lomivorotov 2014; Mackowiak 1992]. Similarly, there was no statistically significant difference for drainage, all causes of infection, renal insufficiency, postoperative MI, and mortality rates between the groups in our study.
Cardiac surgery can be performed under CPB without the need for hypothermia with decent myocardial protection (intermittent blood cardioplegia perfusion, left ventricular venting, short CCs). In a study by Lomivorotov et al, cardiac troponin levels were compared between hypothermic and normothermic CPB patients, and no significant difference was found between the two [Lomivorotov 2014].

Correspondingly, recent studies have not found significant differences in terms of complications indicating cardiac dysfunction such as inotropic need, intraaortic balloon pump (IABP) requirement, low cardiac output syndrome, or arrhythmia (especially atrial fibrillation) between hypothermic and normothermic patient groups [Patel 2012; Ho 2011]. Our study also showed no significant difference in postoperative arrhythmia rates between the two groups. Mean lactate levels and inotropic need of the normothermic group was found to be lower than the hypothermic group. The 
difference was not statistically significant when lactate levels were compared, but was statistically significant for inotropic need in favor of the normothermic group $(P=.01)$.

Anaerobic metabolism is triggered in hypothermia, leading to increased amounts of serum lactate and, in the end, acidosis. Tissue functions become impaired under acidotic conditions. This results in additional need for medications and extra time for correction of clinical parameters when coming off CPB in hypothermia [Ranucci 2006; Ralley 1988].

When the effects of hypothermic $\mathrm{CPB}$ on respiratory functions were studied, Lomivorotov et al found unexpected shorter extubation times for patients undergoing hypothermic bypass [Lomivorotov 2014]. They concluded that shorter extubation times could be related to other factors than temperature. In a study by Sirvinskas et al, the extubation times of patients who were operated on under normothermic conditions were found to be $37 \%$ shorter than those of the hypothermic group [Sirvinskas 2005]. In our study, we also have found that the mean duration of entubation of the normothermic group was shorter than that of the hypothermic group $(9.7 \pm 3.1$ hours and $10.9 \pm 5.8$ hours, respectively), but not statistically significant. In addition, the consciousness, cooperation, and mobilization of patients who were operated on under normothermic conditions were not compromised. When the ICU and hospital stay were compared, it was observed that the durations in the normothermic group were shorter, but this difference was not statistically significant.

One of the organs that is most affected by metabolic changes during CPB is the kidney. Although the incidence of renal failure after cardiac surgery can not be clearly determined, the mortality after surgery may increase 20 fold when renal insufficiency develops [Birch 2017]. In many studies, there was no significant difference between hypothermia and normothermia in terms of renal function after cardiac surgery [Patel 2012; Ho 2011]. This means that normothermic bypass can be safely used without risk of renal dysfunction. When the rates of renal insufficiency were examined (1.5 times or more increase in serum creatinine level in 24-hour measurements), they were found to be lower in the normothermic group. When the blood urea nitrogen (BUN) and creatinine values of the patients were analyzed at discharge time, neither of the groups showed a significant change compared to the preoperative level.

One of the major disadvantages of systemic hypothermia is the dysfunction of the coagulation system, which results in an increase in the risk of bleeding. The adverse effects of the hypothermia on the coagulation system are well proven. The amount of hemorrhage and transfusion required in hypothermic patients during $\mathrm{CPB}$ was reported higher than in normothermic patients in recent studies [Ho 2011; Rasmussen 2007]. Since we consider blood transfusion to be a type of tissue transplantation, we perform open heart surgery without using blood and blood products in our clinical practice to avoid transfusion-related side effects as much as possible, as reported in a previous study [Kaplan 2017].

There was no significant difference between the two groups in means of drainage. The transfusion requirements of the patients in the normothermic group were significantly lower than those of the hypothermic group $(n=31$ [32.3\%] and $\mathrm{n}=34$ [47.9\%], respectively). When the patients who were preoperatively anemic were excluded, the rate of transfusion significantly decreased in the normothermic group (24.4\% in the normothermic group, $44.7 \%$ in the hypothermic group). The reoperation rate in the normothermic group $(9.4 \%, \mathrm{n}=9)$ was significantly lower than in the hypothermic group $(22.5 \%, \mathrm{n}=16)(P=.02, P<.05)$. When the reasons for reoperation (drainage, cardiac tamponade, infection, and sternal detachment) were compared, there was again no significant difference between the two groups.

\section{Our Aim}

We performed operations at $34^{\circ} \mathrm{C}$ or above in the normothermic group, without active cooling. The patient's own heat is the patient's heat measured without active cooling when the $\mathrm{CPB}$ is initiated. Patients in the hypothermic group were operated on at an average temperature of $30.6^{\circ} \mathrm{C}$. Our purpose is not to state the superiority of one to the other, but to present the results of the hypothermic group as we are analyzing the results of normothermic patients. We can not claim that the results favored the normothermic group only as a result of the intraoperative temperature of the patient. Our results show that open heart surgery can safely be performed on normothermic temperatures.

\section{Conclusion}

Although the use of normothermic CPB has found support in recent studies, the use of hypothermia in open heart surgery is still widespread due to the conservative attitudes of surgeons and the difficulty of changing surgical routine practice. We can not explain why the results favored normothermic open heart surgery with only the operating temperature of the patient. With the results of this study, we believe that the cardiac surgery can be safely performed at a patient's own body heat $\left(34^{\circ} \mathrm{C}\right.$ and above) without active cooling and without cardiac and systemic disadvantages.

\section{REFERENCES}

Birch M, Lupei MI, Wall M, et al. 2017. Long-Term Complications and Management. In: Kaplan JA eds. Kaplan's Cardiac Anesthesia 7th ed. 41:1407-24.

Greason KL, Kim S, Suri RM, et al. 2014. Hypothermia and operative mortality during on-pump coronary artery bypass grafting. J Thorac Cardiovasc Surg 148:2712-18.

Ho KM, Tan JA. 2011. Benefits and risks of maintaining normothermia during cardiopulmonary bypass in adult cardiac surgery: a systematic review. Cardiovasc Ther 29:260-79.

Kaplan M, Can T, Karaagac A, et al. 2017. Open cardiac surgery without blood and blood products transplantation. Heart Surg Forum 20:E239-46.

Lomivorotov VV, Shmirev VA, Efremov SM, et al. 2014. Hypothermic versus normothermic cardiopulmonary bypass in patients with valvular heart disease. J Cardiothorac Vasc Anesth 28:295-300.

Mackowiak PA, Wasserman SS, Levine MM. 1992. A critical appraisal of 98.6 degrees $\mathrm{F}$, the upper limit of the normal body temperature, and other legacies of Carl Reinhold August Wunderlich. JAMA 268:1578-80. 
Patel PA, Desai ND. 2012. Con: Cardiac surgery should be performed under warm conditions. J Cardiothorac Vasc Anesth 26:949-51.

Ralley FE, Wynands JE, Ramsay JG, et al. 1988. The effects of shivering on oxygen consumption and carbondioxide production in patients revarming from hypothermic cardipulmonary bypass. Can. J. Anaesth 35:332-37.

Ranucci M, De Toffol B, Isgro G, et al. 2006. Hyperlactatemia during cardiopulmonary bypass: determinants and impact on postoperative outcome. Crit Care Med 10:R167
Rasmussen BS, Sollid J, Knudsen L, et al. 2007. The release of systemic inflammatory mediators is independent of cardiopulmonary bypass temperature. J Cardiothorac Vasc Anesth 21:191-96.

Sirvinskas E, Nasvytis L, Raliene L, et al. 2005. Myocardial protective effect of warm blood, tepid blood, and cold crystalloid cardioplegia in coronary artery bypass grafting surgery. Croat Med J 46:879-88.

Warm Heart Investigators. 1994. Randomised trial of normothermic versus hypothermic coronary bypass surgery. Lancet 343:559-63. 